\title{
The resurgence of tuberculosis in the Republic of Ireland: Perceptions and reality
}

\author{
Dennis Pringle* \\ Department of Geography, National University of Ireland, Maynooth, Co. Kildare, Ireland
}

\section{A R T I C L E I N F O}

Article history:

Available online 26 December 2008

Keywords:

Ireland

Tuberculosis

Migrants

Media

Drug resistance

Immigration

\begin{abstract}
A B S T R A C T
Tuberculosis remained a very significant cause of death in Ireland until the mid-20th century and still occupies a prominent position in the folk memory. As I show with reference to recent Irish media coverage, the global resurgence of tuberculosis is therefore viewed with concern in Ireland. Using data collated by the Health Protection Surveillance Centre between 1998 and 2005 however, I show that the recent increase in tuberculosis incidence in Ireland is less than is popularly perceived. This increase is largely associated with economic immigrants attracted to Ireland by the 'Celtic Tiger' economic boom, but there is little evidence to suggest that this has had a negative impact on the Irish-born population. Drug resistance is still a small but growing problem. Whilst vigilance is required, it is argued that the recent increase does not at present indicate a likely return to the situation in the mid-20th century.
\end{abstract}

(c) 2008 Elsevier Ltd. All rights reserved.

\section{Introduction}

Tuberculosis is an ancient disease. Its exact origins are unknown, but it seems likely that humans were infected when they started living in close proximity to cattle during the agricultural revolution in the Neolithic (Karlen, 2000). But whatever its origins, tuberculosis (also known as consumption or phthisis) remained one of the leading causes of death throughout most of history. Although mortality rates began to decline in developed countries in the 19th century, they still remained significant well into the 20th century, but the introduction of effective drugs, such as streptomycin in 1944, isoniazid in 1952 and rifampicin in the 1970s, raised hopes that tuberculosis could eventually be defeated. Its global resurgence in the early 1980s, due to a myriad of factors, was consequently a source of dismay and concern, resulting in it being declared a global health emergency by the WHO in 1993.

This resurgence is thought to be connected with the emergence of HIV infection. Infection by the causal agent (Mycobacterium tuberculosis) does not necessarily result in active tuberculosis. In a majority of cases the infected cells are surrounded by macrophages, B and T lymphocytes and fibroblasts to form a granuloma which in effect seals in the infection (Playfair, 2004). The immune system is thereby able to contain the infection and stop it from spreading, either within the infected person or to other people. Many infected people carry latent tuberculosis for the remainder of their lives without any obvious symptoms. However, if their immune system becomes compromised, for example by drug

\footnotetext{
* Tel.: +353 1 7083685; fax: +35317083573

E-mail address: dennis.pringle@nuim.ie
}

abuse, dietary deficiencies, old age or HIV infection, then the immune system may no longer be able to contain the infection which may then become active. Left untreated, active tuberculosis is frequently fatal. It may also be transmitted to others, resulting in new infections. HIV infection therefore has serious implications not only for those already carrying a latent infection, but also for other people not already infected by tuberculosis.

Drug resistance has also contributed to the global resurgence. As low-cost drugs have become less effective, tuberculosis may be left untreated in developing countries where the cost of effective treatments remains prohibitive. This, in turn, results in further new infections (Desowitz, 2002). In some instances apparent prevalence rates may have increased due to better surveillance, but in other cases the real prevalence rates may have increased due to a deterioration in the public health systems (Garrett, 2001).

There are indications that the most recent pandemic may have peaked around 2005, but the absolute number of people with tuberculosis is larger now than at any point in history. An estimated 2 billion people (or one person in three worldwide) carry the bacillus, resulting in 8.8 million new cases of active tuberculosis and 1.6 million deaths in 2005 (World Health Organization, 2007).

Although Ireland has largely escaped the worst of the new wave of tuberculosis, its resurgence elsewhere is a source of concern. Tuberculosis occupies a prominent position within the Irish psyche because it remained a major cause of death in Ireland much later than elsewhere. Ireland actually had lower tuberculosis mortality rates than Britain in the mid-19th century (despite the horrendous living conditions generated in Ireland by the Great Famine in the 1840s), but tuberculosis mortality rates increased in Ireland throughout the second half of the 19th century at a time when they 
were falling in Britain. By the end of the century, Ireland experienced considerably higher tuberculosis mortality than either England or Scotland (Countess of Aberdeen, 1908). There was some reduction in mortality in the first half of the 20th century, but the disparity between Ireland and Britain continued to widen due to the much more rapid improvement in Britain. For example, the crude death rate in Ireland in 1922 was 153 per 100,000, compared with 112 in England and Wales (Jones, 2001). Tuberculosis remained one of the major causes of death in Ireland as late as the 1940s, with the annual crude rate varying between 125 and 147 per 100,000 between 1940 and 1945 (Deeny, 1954). However, the introduction of streptomycin and other antibiotics brought about a major transformation in the 1950s. Whilst incidence and mortality rates subsequently declined to a small fraction of what they had been previously, the trauma associated with tuberculosis still remains fresh in the memory of many of its older citizens. The global resurgence in tuberculosis is consequently topical and receives significant media coverage. For example, the Irish Times published 59 articles in 2007 which contained a reference to tuberculosis. Some of these were only passing mentions in articles on historical figures who had developed tuberculosis at some stage in their lives, but a majority reported on contemporary issues affecting either less developed countries or Ireland.

Four themes may be detected in the media coverage:

1. Tuberculosis rates are now increasing in Ireland after a lengthy decline, with an implicit threat that we could see a return to the 'bad old days'.

When compared with 2001 figures, there was a 7.1pc increase in the TB notifications in 2002. (Anonymous, 2004a)

This is a disease that many thought had been banished forever from Ireland ... Tuberculosis wreaked havoc with the lives of thousands of Irish people for generations until tackled seriously by the Health Plan of the late Dr Noel Browne, as Heath Minister in the 1950s. (Anonymous, 2001)

Whether it's lung cancer, asthma, chronic obstructive pulmonary disease, tuberculosis or cystic fibrosis - the picture is the same; death rates and prevalence are either rising or higher than they should be and the resources to effectively prevent, diagnose and treat these diseases are inadequate. (Houston, 2008)

\section{The recent increase in Ireland is associated with new immigrants.}

A World Health organisation survey of more than 67,000 TB patients in 77 countries, published in Brussels, identifies three new member states - Latvia, Lithuania and Estonia - as among those in eastern Europe and Central Asia where multi drug-resistant TB, known as MDR-TB, is rampant. (Anonymous, 2004b) Although Africa has only 11 per cent of the world's population, it accounts for more than a quarter of the nine million active TB cases and two million deaths caused every year by the disease. It is also the only continent where infection rates are increasing every year. (Anonymous, 2005)

\section{The upsurge in tuberculosis is fuelled by HIV infection.}

You are 200 times more likely to develop TB if you have HIV than if you didn't, and multi-drug resistant TB is linked to people with HIV who are more difficult to treat because they have drug intolerance. (Dempsey, 2003)

4. Tuberculosis is becoming more difficult to treat due to drug resistance.

"A new form of tuberculosis, resistant to most current drug therapies and described by the World Health Organisation as 'virtually incurable' in developing countries, has been detected in Irish patients. ... Ireland has between five and 10 cases (of MDR-TB) a year. We know that will increase. It's inevitable." (Ahlstrom \& O'Sullivan, 1997)

This paper assesses the extent to which the concerns propagated by the media with regard to each of these themes accurately reflect the situation in Ireland.

\section{Data sources}

Tuberculosis is a notifiable disease in Ireland under the Infectious Disease Regulations 1981 (and subsequent amendments). Only symptomatic cases are reported (National Disease Surveillance Centre, 2003), but in theory every clinically and/or radiologically diagnosed case displaying symptoms should be reported to a Medical Officer of Health (usually the Director of Public Health for the local area). This information is collated by the Health Protection Surveillance Centre (HPSC) - formerly the National Disease Surveillance Centre (NDSC) - which publishes summary statistics in an annual Report on the Epidemiology of Tuberculosis in Ireland (available on-line at http://www.ndsc.ie/hpsc). This provides a statistical breakdown on a number of features in addition to incidence and mortality rates. The first report, for 1998, was published in 2000, but it included figures calculated retrospectively back to 1991. The most recent report provides information for 2005. Mortality figures are also available from the Report on Vital Statistics, published annually by the Central Statistics Office (CSO) (and available on-line at http://www.cso.ie). The HPSC uses a conservative EU-based clinical definition of tuberculosis, whereas the CSO estimates of mortality from tuberculosis are based on death certification and are normally slightly higher than the estimates reported by the HPSC. However, they follow the same trends as the HPSC reported mortality figures. This paper focuses on the data provided by the HPSC.

$65.7 \%$ of the cases reported during the period 1998-2005 were pulmonary, $25.2 \%$ were extrapulmonary, and $7.6 \%$ were both pulmonary and extrapulmonary. These percentages remained fairly stable throughout the study period. $65.9 \%$ of the pulmonary cases were confirmed either by isolation of $M$. tuberculosis complex (except Mycobacterium bovis BCG) from any clinical specimen whilst $43.7 \%$ were laboratory confirmed by microscopic identification of acid-fast bacilli in spontaneous or induced sputum. $69.6 \%$ of all cases were confirmed by one method or both, whilst the unconfirmed cases were fairly evenly divided between those testing negatively (15.6\%) and those where testing was not done or the outcome was not reported (14.8\%). The percentage testing positively increased during the study period from a low of $61.0 \%$ in 1998 to a high of $72.6 \%$ in 2004 , with the biggest change occurring between 2001 and 2003.

This study reports the figures for all notified cases, whether pulmonary or extrapulmonary and whether confirmed or otherwise.

\section{Incidence rates}

The number of tuberculosis notifications and the crude incidence rates for 1991-2005 are graphed in Fig. 1. The general pattern in both graphs is, not surprisingly, similar. There was a decline throughout the 1990s, except for a 'spike' in 1998 and 1999. It is not clear whether this indicates an actual increase in incidence in these years or whether it may simply reflect a change in the notification procedures associated with the early publication of the annual reports. The downward trend resumed in 2000 before bottoming out in 2001. The general trend since 2001 has been upward, 

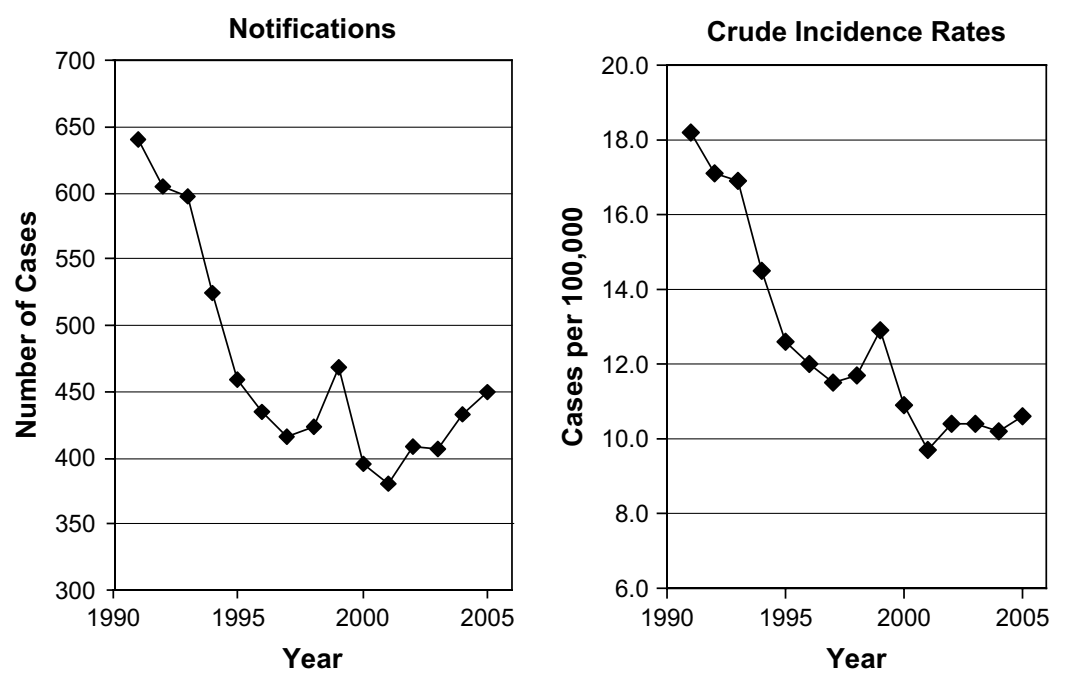

Fig. 1. Pulmonary and extrapulmonary tuberculosis notifications and incidence rates, 1991-2005.

supporting the notion of a deteriorating situation. However, the increase in incidence is less marked than the increase in the number of cases, suggesting that the increase in cases may simply reflect a very rapid increase in population. Also, whilst these recent trends are in the 'wrong' direction, the absolute number of cases and incidence rates (per 100,000) remain low, both historically and in comparison with other European countries (World Health Organization, 2008). The increases may even be artifactual and simply reflect improvements in the notification and surveillance procedures. Also, even if the increases are accepted as genuine, it should be noted that the incidence rate in 2005 was less than those in the mid-1990s, when tuberculosis was still generally considered to have been defeated. Thus, whilst we may have the beginnings of a problem, it would appear premature to describe it as a crisis.

\section{The New Irish}

Ireland's demographic history over the past two centuries was predominantly one of out-migration and population decline. Mass emigration was triggered by the Famine in the 1840s, but continued at a lower although still substantial rate throughout most of the 20th century, producing a net population decline that persisted until the 1960s, despite a net natural increase (i.e. an excess of births over deaths) throughout most of this period. This downward trend in total population was eventually reversed around 1962. However, although total population has persistently increased since the early 1960s, out-migration continued to exceed inmigration until the mid-1990s, apart from a brief interlude in the late 1970s when there was a short period of net in-migration (mainly comprised of returned emigrants). As a result, Ireland, in contrast to most west European countries, had a very small immigrant population as late as the mid-1990s. The overwhelming majority of people living in Ireland at that time were either Irishborn or of Irish descent.

This situation has changed dramatically since 1996 due to large-scale in-migration associated with an economic boom (the so-called 'Celtic Tiger'). Some of the new immigrants were returned emigrants, taking advantage of the improved economic situation to return home, but many of them had no previous Irish connections. The percentage of people born outside Ireland or the UK (many of whom are Irish nationals) increased from $1.7 \%$ in 1996 to $8.2 \%$ in 2006 (Central Statistics Office, 2007).

Relations between the Irish-born and the foreign-born remain quite good - at least as perceived from the perspective of the Irishborn. Whilst language differences provide a barrier to integration, there is little evidence so far of overt racial or ethnic tensions. The new immigrants are predominantly young, and (especially the East Europeans) are generally perceived as hard-working, industrious and polite. However, the extent and unprecedented nature of these changes is creating a rapidly changing context with new anxieties, so there may be a degree of latent xenophobia. The idea that tuberculosis could be reintroduced into Ireland by foreigners could therefore feed certain unarticulated prejudices.

The HPSC reports provide figures on place of birth of tuberculosis patients. These indicate that the burden of tuberculosis falls more heavily on the foreign-born population - i.e. there is a higher incidence amongst the foreign-born (24.8 per 100,000 as compared with 8.3 per 100,000 for the Irish-born in 2005). This may reflect poorer living conditions amongst the foreign-born within Ireland, but given the extent of the differences in incidence rates between different immigrant groups (which are not reflected by corresponding differences in living conditions), it is more likely to indicate that they are already infected when they arrive.

The expectation of many Irish is that tuberculosis incidence amongst immigrants would be highest amongst Africans due to HIV. However, the incidence is almost as high for Asians. Africans account for $32.3 \%$ of the non Irish-born tuberculosis cases, but represent only $7.0 \%$ of the immigrant population; Asians account for $39.4 \%$ of non Irish-born tuberculosis cases, but represent only $9.1 \%$ of immigrant population. There are major variations within each group. Nigerians are the largest tuberculosis group amongst the African-born, but they are also the largest African immigrant group, so their incidence rate is not exceptionally high by African standards. Indians and Pakistanis are the largest TB groups amongst the Asian-born, whereas other Asian groups (e.g. the Chinese) have much lower rates. Within the European immigrants, tuberculosis rates are high for Romanians, but low for Poland and the Baltic states who comprise a much larger percentage of the total immigrant population.

The total number of notifications for Irish- and foreign-born persons each year from 1998 to 2005 is graphed in Fig. 2. The absolute number and percentage of cases amongst the foreign-born have generally increased but, although the total number of cases has increased since 2001, it is noticeable that the absolute number of cases amongst the Irish-born has generally continued to decline. In other words, the increase in the total number of notifications is solely attributable to the increase in cases amongst foreign-born residents. This, in turn, may simply reflect the rapidly increasing size of the foreign-born population. While this would suggest that tuberculosis notifications are increasing due to the growth in the 


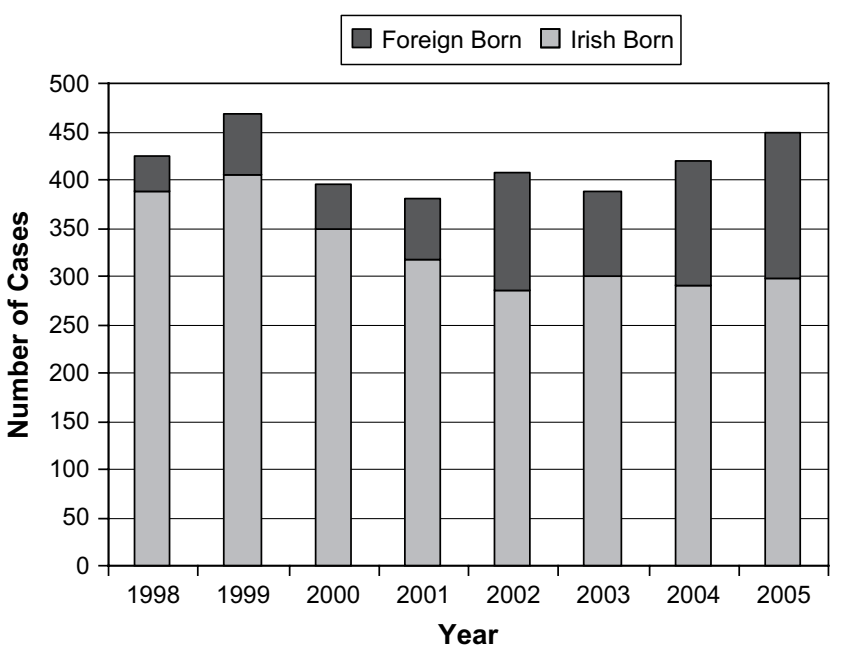

Fig. 2. Place of birth of all notified cases of pulmonary and extrapulmonary tuberculosis, 1998-2005.

immigrant populations, it also suggests that this is not resulting in a significant number of infections amongst the Irish-born arising from contacts with the new immigrants.

This conclusion receives support if one considers the age profiles of the Irish- and foreign-born cases. Fig. 3 shows the age breakdown for 2004 . The age profiles are clearly quite different. The median age for foreign-born patients in 2004 was 29.6, whereas for the Irish-born patients it was 50.3. This suggests that many of the Irish-born patients are elderly people who may have had latent TB for decades, rather than being recently infected by new immigrants.

There was an increase in the age specific incidence rates for people aged 15-24, 25-34 and 35-44 between 1998 and 2005, but a decline for all other age groups. The increases in these three age groups would again appear to suggest that they are associated with immigrant populations, whereas the decline in the other age groups would suggest that the incidence of tuberculosis is continuing to decline in the Irish-born population, even in the most susceptible age groups.

Overall, the evidence would suggest that the recent increase in tuberculosis incidence is associated with immigrant populations, but that this has not had significant implications for the Irish-born population.

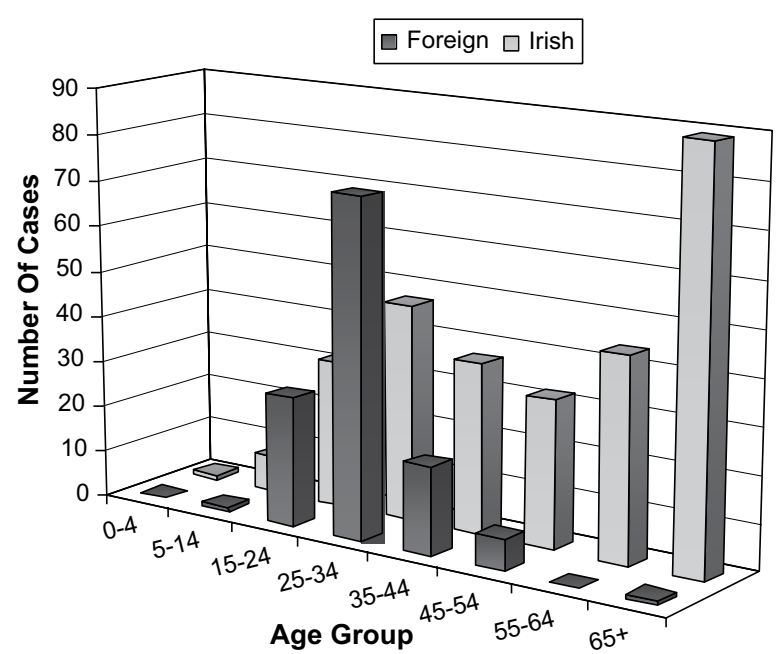

Fig. 3. Age distribution of Irish- and foreign-born pulmonary and extrapulmonary tuberculosis cases, 2004.

\section{HIV infection}

The cumulative number of known HIV infections in Ireland up to the end of June 2007 was 4623, resulting in 941 cases of AIDS, of which 402 had died (Health Protection Surveillance Centre, 2007). The number of new AIDS cases (reflecting earlier infections) peaked in the early- to mid-1990s, but there was a fourfold increase in new HIV infections between 1998 and 2003, resulting in a renewed upsurge in AIDS cases. The number of new HIV infections and AIDS diagnoses would now appear to be declining since 2003/2004. This 'second epidemic' is largely associated with new immigrants. For example, $42 \%$ of new HIV cases in the first two quarters of 2007 for whom information on 'geographic origin' is available were from Sub-Saharan Africa, whilst a further $18 \%$ were from other countries. The upsurge in HIV infections between 1998 and 2003 was paralleled by a similar upsurge in infections through heterosexual contacts, whereas new cases arising from intravenous drug use or male-male sexual contacts (pathways associated more with the Irish-born) increased only slightly.

The implications of HIV infection for tuberculosis within Ireland are unclear. Only 24 of the 882 new cases in 2004 and 2005 were reported to be infected by HIV, but no information was available on 830 of these cases. However, there are grounds for suspecting that HIV infection within Ireland may not be a major factor for the increasing number of tuberculosis cases. HIV may be a significant factor for those from Sub-Saharan Africa who were already carrying the tubercle bacillus when they arrived in Ireland, but HIV rates in Ireland are low for persons from other countries that provide the largest numbers of foreign-born tuberculosis cases. Also, within Ireland there is a mismatch in the regional patterns of tuberculosis and HIV: HIV incidence is much higher in the east, whereas tuberculosis incidence tends to be as high or higher in the south and west. One must always be wary of the ecological fallacy, but there is little to suggest that HIV infection is a major factor in the incidence of tuberculosis in Ireland.

\section{Drug resistance}

The fourth concern articulated by the media is that tuberculosis may be becoming less amenable to treatment as $M$. tuberculosis develops resistance to the drugs used to treat it. Several levels of resistance may be identified. Resistance to the two main drugs used in the treatment of tuberculosis (isoniazid and rifampicin) is referred to as multiple drug resistance (MDR-TB); resistance to isoniazid and rifampicin, plus resistance to a quinolone and at least one other second line drug is referred to as extensively drug resistance (XDR-TB). The fear in Ireland, as elsewhere, is that TB could become untreatable. Indeed, the first case of complete drug resistance (CDR-TB), in which the patient failed to respond to every known drug, was reported in Italy in early 2007 (McKenzie, 2007).

Data provided by HPSC suggests that the problem remains small in Ireland in comparison with other countries, although it will almost certainly become a more serious problem in the future. Only $4.6 \%$ of the isolates tested over the period 1998-2005 showed resistance to any drugs. In most cases they showed resistance to only one drug. In fact, over this period there was a total of only 12 cases of MDR-TB and one case of XDR-TB. Of the isolates showing drug resistance, $79 \%$ showed resistance to isoniazid, $17 \%$ to rifampicin, $26 \%$ to streptomycin, $11 \%$ to pyrazinamide and $8 \%$ to ethambutol.

Despite this generally positive situation, there are a couple of disturbing trends. First, although there has not been a noticeable increase in MDR-TB, there has been an increase in resistance to a single drug (especially isoniazid). The second is that a disproportionate percentage of resistant strains (57\%) were isolated from 
foreign-born patients, suggesting that drug resistance may be being imported from elsewhere.

\section{Discussion}

Curtis (2004), in a review of several studies of tuberculosis in Britain and the US in the 1990s, notes that prevalence rates were generally higher amongst ethnic minorities, but that there was little evidence to suggest these rates were transmitted to the majority populations. This finding is supported by the recent experience in Ireland. However, the studies reported by Curtis also suggest that the higher prevalence amongst ethnic minorities was primarily a function of their poorer living conditions (i.e. crowding, poverty) rather than migration. This needs to be explored in more detail, but the indications in Ireland are that tuberculosis is being 'imported' (e.g. prevalence rates in Ireland are higher for immigrant groups from high prevalence countries than for immigrant groups from low prevalence countries living in similar social conditions).

Thomas McKeown argued that the decline in mortality from tuberculosis in England and Wales could be traced back to the 1840s (and possibly even earlier) (McKeown, 1976, 1979, 1988). Although the introduction of streptomycin in the 1940s brought about a significant acceleration in the rate of decline, most of the improvement with regard to reduced mortality in England and Wales had already occurred long before the introduction of antibiotics. Similar tends in most other infectious diseases led McKeown to argue that medical interventions played a relatively insignificant role in the epidemiological transition from high mortality caused by infectious diseases to lower mortality later in life primarily associated with non-infectious diseases. This transition, he argued, owed more to people developing more effective immune systems due to an improved diet and better living conditions. Several critics, most notably Szreter (1988), argued that McKeown overstated the importance of economic progress and underestimated the impact of public health reforms, but there is a widespread acceptance of his argument that advances in therapeutic medicine arrived too late to explain the reduction in mortality from infectious diseases and a corresponding increase in life expectancy.

The situation in Ireland with regards to tuberculosis appears to be somewhat different. Tuberculosis remained a very significant cause of death in Ireland into the 1950s. This is probably because living conditions failed to improve in Ireland at the same rate as they did in Britain. Indeed, this failure is one of the major reasons for the predominance of net out-migration in Ireland through to the mid-1990s. The decline of tuberculosis in Ireland was therefore much later than in Britain and owed more to direct medical interventions.

However, the socio-economic context has changed. The economy has been steadily improving since the 1960s and the past decade saw a dramatic increase in living standards as a result of the Celtic Tiger and a reversal of migration flows resulting in very heavy in-migration. Thus, if McKeown's ideas are correct (or even those of his critics), it is very unlikely that tuberculosis could ever pose the threat that it once did following the country's recent rapid increase in prosperity.

Although tuberculosis occupies a special place in the Irish psyche because of its relatively recent history, the evidence would suggest that it should not be a major source of concern. However, it is important to avoid complacency and to remain vigilant. We may be witnessing the beginnings of a more serious situation, associated with sections of the new immigrant population. Given the prominent position that tuberculosis occupies within the Irish folk memory, there is a risk that the fears generated by resurgent tuberculosis could translate into more overt forms of xenophobia (despite the lack of evidence to suggest that the Irish-born are adversely affected). It is therefore essential to ensure access to effective treatment for all members of the population, especially the new immigrants, if we are to continue to minimise the threat posed by drug resistance. Failure to do so could generate a xenophobic reaction which would drive the problem underground and make it much more difficult to contain.

\section{Acknowledgments}

I would like to acknowledge the helpful comments by Dr. Malachy McCann and unknown referees on an earlier draft of this paper.

\section{References}

Ahlstrom, D., \& O'Sullivan, K. (23rd October 1997). Ireland's TB strategy ready to deal with new superbug. Irish Times.

Anonymous. (24th April 2001). Vigilance necessary 'to keep TB at bay'. Irish Independent.

Anonymous. (21st December 2004). Watch on levels of TB vital, disease watchdog warns. Irish Independent.

Anonymous. (16th March 2004). Deadly TB strain in EU accession countries. Irish Times.

Anonymous. (26th August 2005). Ministers declare TB an African emergency. Irish Times.

Central Statistics Office. (2007). Usual residence, migration, birthplaces and nationalities. In: Census 2006, Vol. 4. Dublin: Stationary Office.

Countess of Aberdeen. (1908). Ireland's crusade against tuberculosis. Dublin: Maunsell.

Curtis, S. (2004). Health and inequality: Geographical perspectives. London: Sage.

Deeny, J. (1954). Tuberculosis in Ireland. Dublin: Medical Research Council.

Dempsey, A. (3rd November 2003). The disease that time forgot. Irish Times.

Desowitz, R. S. (2002). Federal bodysnatchers and the New Guinea virus. Tales of parasites, people and politics. New York: Norton.

Garrett, L. (2001). Betrayal of trust. The collapse of global public health. New York: Hyperion.

Health Protection Surveillance Centre. (2007). HIV and AIDS in Ireland. Quarters $1 \mathcal{E}$ 2 2007. Dublin: Health Protection Surveillance Centre.

Houston, M. (27th February 2008). State's death rate from respiratory disease is second highest in Europe. Irish Times.

Jones, G. (2001). Captain of all these men of death: The history of tuberculosis in nineteenth and twentieth century Ireland. In: Clio Medica, Vol. 62. Amsterdam: Wellcome Series in the History of Medicine, Rodopi Bv Editions.

Karlen, A. (2000). Plague's progress. A social history of man and disease. London: Phoenix.

McKenzie, D. (2007). The white plague. New Scientist, 193(2596), 44-47.

McKeown, T. (1976). The modern rise of population. London: Edward Arnold.

McKeown, T. (1979). The role of medicine: Dream, mirage or nemesis? Oxford: Blackwell.

McKeown, T. (1988). The origins of human disease. Oxford: Blackwell.

National Disease Surveillance Centre. (2003). Case definitions for notifiable diseases. Dublin: National Disease Surveillance Centre.

Playfair, J. (2004). Living with germs in sickness and health. Oxford: Oxford University Press.

Szreter, S. (1988). The importance of social intervention in Britain's mortality decline c. 1850 1914: a reinterpretation of the role of public health. Social History of Medicine, 1, 1-37.

World Health Organization. (2007). Global tuberculosis control: Surveillance, planning, financing. WHO Report 2007. Geneva: World Health Organization. (WHO/ HTM/TB/2007.376).

World Health Organization. (2008). Health for all database (HFA-DB). Copenhagen: WHO Regional Office for Europe. Available from. http://www.euro.who.int/hfadb. 